\title{
Removal of arsenic from wastewater treated by means of nanoparticles and magnetic separation
}

\author{
M.F. Isela ${ }^{1}$, R.C. Mercedes E. ${ }^{1} \&$ G.M. Rocío ${ }^{2}$ \\ ${ }^{1}$ Posgrado de Ingeniería, UNAM, Instituto Mexicano de Tecnología del Agua, Jiutepec, Mor., Mexico \\ ${ }^{2}$ Centro de Ciencias de la Atmósfera, UNAM, Ciudad Universitaria, Coyoacán, Mexico
}

\begin{abstract}
This work is carried out based on the importance of the enormous consumption of water, which is obliged to comply with current regulations for the use to which it is intended. Because the arsenic is a toxic element and exposure to it, even in small amounts, can cause serious health problems, the water supplied to the services must comply with the maximum permissible limits. Therefore, it will use two iron oxide nanoparticles that allow the elimination of said pollutant and, in turn, the nanoparticles will be recovered through the application of a magnetic field for its regeneration and subsequent reuse, determining its life cycle. By establishing the optimal adsorption conditions for each of the nanoparticles, the removal of arsenic in a contact device waternanoparticles - magnetic field using only the most efficient nanoparticles and the use wastewater treated real will be carried out.
\end{abstract}

\section{INTRODUCTION}

Arsenic (As) is a natural element from earth's crust; widely distributed through all the environment. Ingestion of small amounts of As can cause chronic effects due to its bioaccumulation in the organism. Prolonged exposure to inorganic As, through the consumption of contaminated water or food prepared with it and food crops watered with As-rich water can cause chronic intoxication.

The treatment train that municipal wastewater in Mexico receives includes physical, chemical and biological processes generally, under the operating conditions in which these processes are realized, certain pollutants, such as heavy metals, are not removed (Abejón \& Garea, 2015).

Nanoparticles (NPs) are materials with a nanometric size on its three dimensions; as a result of its small size, they possess structural and morphological characteristics which make them ideal for some kind of applications. Specifically, magnetic NPs are efficient for As polluted water treatment up to the grade of obtaining water suitable for human consumption, sanitizing and irrigation. Due to the big use of superficies in proportion to its volume and they link easily to chemical substances, they can be eliminated, applying a magnetic field (Liyun et al., 2012; Yavuz et al., 2006).

Magnetic NPs base on iron, both magnetic and oxidized iron offer stronger magnetic susceptibility, high chemical stability, and low toxicity, so its use on water treatment results efficient, obtaining water with As concentrations under maximum level permissions established by Mexican Official Norms (NOM-127-SSA1-1994).
Table 1. NPs to use

\begin{tabular}{lll}
\hline NPs & Description & $\begin{array}{l}\text { Physical } \\
\text { appearance }\end{array}$ \\
\hline $\begin{array}{l}\text { Iron oxide } \\
\left(\mathrm{Fe}_{2} \mathrm{O}_{3}\right)\end{array}$ & $\begin{array}{l}\text { Magnetic and } \\
\text { semiconductor NPs }\end{array}$ & $\begin{array}{l}\text { Fine reddish } \\
\text { powder without } \\
\text { characteristid } \\
\text { aroma } \\
\text { Braphene }\end{array}$ \\
$\begin{array}{l}\text { Gunctionalized } \\
\text { with } \mathrm{Fe}_{2} \mathrm{O}_{3}\end{array}$ & $\begin{array}{l}\text { Graphene microflake } \\
\text { reduced and } \\
\text { functionalized with } \\
\mathrm{Fe}_{2} \mathrm{O}_{3}(2 \% \text { a } 5 \%)\end{array}$ & \\
\hline
\end{tabular}

\section{METHODOLOGY}

\subsection{Selection of parameters}

This first stage will be carried out using commercial iron oxide NPs (Table 1), model solutions of wastewater treated with known concentrations of As was prepared.

The optimal work parameters will be established: concentration As-dose NPs, $\mathrm{pH}$, temperature, agitation and contact time. In order to identify which of the NPs has a greater capacity for removing As kinetics and isotherms of adsorption will be carried out with each of them.

\subsection{Design of contact device}

Once the working parameters have been optimized and NPs have been identified that allow for greater elimination of As, a prototype device at laboratory scale 


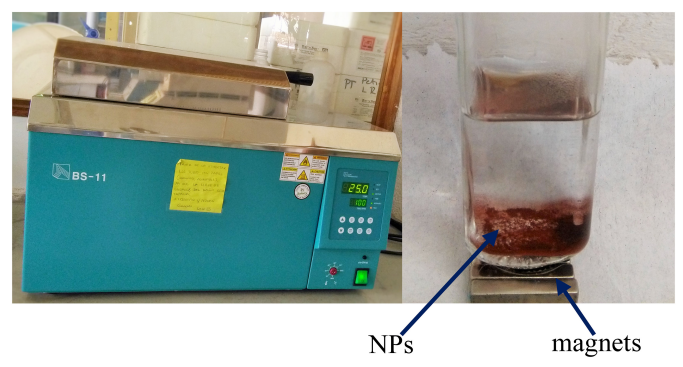

Figure 1. Experimental system for adsorption tests.

will be designed and assembled to evaluate the best contact between these NPs and the water. In this stage, real samples of treated wastewater will be used to evaluate the effects due to interferences in the elimination process.

A magnetic device will be assembled together to allow separation of the NP from the water in process. After this separation, the analysis of the effluent will be carried out by Atomic Absorption Spectrophotometry.

\subsection{Regeneration of NPs}

For the regeneration study of the NPs, an acid wash will be carried out, eliminating the As, centrifuged and reused the NPs, determining its adsorption capacity after each use, thus obtaining its life cycle.

\section{RESULTS AND DISCUSSION}

The experimental system for the adsorption tests consists of $150 \mathrm{~mL}$ glass bottles. A continuous oscillatory agitation device at $100 \mathrm{rpm}$ is used, with a sample volume of $100 \mathrm{~mL}$, this adsorption process will be carried out with different doses of the NPs under study, at room temperature $\left(25^{\circ} \mathrm{C}\right)$. Samples are taken at different contact time intervals $(1,5,8,15,24,36,48,72$, $96 \mathrm{~h})$. Once this time has elapsed, a magnetic field is applied with the objective of separating the NPs from the water and proceeding to a filtration of the sample, using Whatman ${ }^{\circledR}$ filter paper $(45 \mu \mathrm{m})$, eliminating the color of the treated water. All tests will be done in triplicate (Fig. 1).
The residual concentration of As in the effluent will be quantified, in this way both the kinetics and the adsorption isotherms will be obtained.

So far, a removal percentage of $94.67 \%$ has been obtained in $48 \mathrm{~h}$, using an As concentration of $1.5 \mathrm{mg} \mathrm{L}^{-1}$ in synthetic water and a dose of NPs of $1 \mathrm{~g} \mathrm{~L}^{-1}$. A greater removal is expected based on what is reported in the literature. It is worth mentioning that an average $\mathrm{pH}$ value of 8.02 was obtained for the effluent, which is why it is not an additional parameter to be modified in the effluent.

\section{CONCLUSIONS}

With the concentration of As that has been used for the synthetic water $\left(1.5 \mathrm{mg} \mathrm{L}^{-1}\right)$ and the dose of NPs of $\mathrm{Fe}_{2} \mathrm{O}_{3}\left(1 \mathrm{~g} \mathrm{~L}^{-1}\right)$ the feasibility of the removal of said metal is verified, nevertheless, it is necessary to continue with experimentation to find the equilibrium conditions.

The agitation imposed on the system (100 rpm) makes it possible to keep the NPs in suspension, which improves the contact surface, although it is worth mentioning that after certain hours the nanoparticles sedimented, so this parameter must also be optimized.

\section{REFERENCES}

Abejón, R. \& Garea, A. 2015. A bibliometric analysis of research on arsenic in drinking water during the 1992-2012 period: an outlook to treatment alternatives for arsenic removal. J. Water Process Eng. 6: 105-119.

Liyun, F., Minhua, C., Xiaoyu, M., Zhu, Y. \& Hu C. 2012. Superparamagnetic high-surface-area $\mathrm{Fe}_{3} \mathrm{O}_{4}$ nanoparticles as adsorbents for arsenic removal. J. Hazard. Mater. 217-218: 439-446.

Official Mexican Standard. NOM-127-SSA1-1994 (as amended in 2000). Environmental health, water for human use and consumption - permissible quality limits and treatments to which water must be submitted for drinking water. Mexico.

Yavuz, C.T.J., Mayo, T., Yu, W.W., Prakash, A., Falkner, J.C., Yean, S., Cong, L., Shipley, H.J., Kan, A., Tomson, M., Natelson, D. \& Colvin, V.L. 2006. Low-field magnetic sep-aration of monodisperse $\mathrm{Fe}_{3} \mathrm{O}_{4}$ nanocrystals. Science 314(5801): 964-967. 


\title{
A synergistic $\mathrm{Cu}-\mathrm{Al}-\mathrm{Fe}$ nano adsorbent for significant arsenic remediation and $\operatorname{As}(0)$ supported mitigation in aqueous systems
}

\author{
Y.K. Penke ${ }^{1}$, G. Anantharaman ${ }^{2}$, J. Ramkumar ${ }^{3}$ \& K.K. Kar ${ }^{3}$ \\ ${ }^{1}$ Materials Science Programme, IIT Kanpur, India \\ ${ }^{2}$ Department of Chemistry, IIT Kanpur, India \\ ${ }^{3}$ Department of Mechanical Engineering, IIT Kanpur, India
}

\begin{abstract}
In this work arsenic adsorption in aqueous systems is studied onto copper based ternary metal oxide ( $\mathrm{Cu}-\mathrm{Al}-\mathrm{Fe})$ nano adsorbents. In vibrational spectroscopy analysis, various As- $\mathrm{O}$ and $\mathrm{As}-\mathrm{OH}$ related stretching vibrations were observed in $800-850 \mathrm{~cm}^{-1}$ band. Adsorption kinetics study is observed with Pseudo Second Order (PSO) model and Freundlich model is observed for adsorption isotherms. Quantitative studies infer better As(III) adsorption in basic conditions and better $\mathrm{As}(\mathrm{V})$ adsorption in acidic conditions. XPS study of individual As(3d) spectra observed with multiplet peak behavior attributed various arsenic signals. In adsorbed systems significant proportions of $\mathrm{As}(0)$ signals are observed around 10 at.\% for both $\mathrm{As}(\mathrm{III})$ and $\mathrm{As}(\mathrm{V})$ systems in $\mathrm{pH}$ 7 condition. Active redox behavior of $\mathrm{Cu}-\mathrm{Al}-\mathrm{Fe}$ resulted in better $\mathrm{As}(\mathrm{III})$ mitigation effect ability.
\end{abstract}

\section{INTRODUCTION}

Arsenic contamination in the South-Asian nations (India, Bangladesh, Pakistan etc.) is considered to be one of the largest mass poising incidents of human in history. This contamination scenario is affecting around 150-200 million population by means of different health disorders (Yan, 2012). Different types of arsenic remediation processes are in use for various purposes to reduce the final arsenic to less than $10 \mu \mathrm{g} \mathrm{L}^{-1}$ (WHO guidelines). Adsorption based arsenic remediation method is considered to be one of the efficient and economical processes. Zero valent iron (ZVI) and pyrites $\left(\mathrm{FeS}_{2}\right)$ adsorbent systems were known for arsenic remediation by means of redox (i.e., simultaneous reduction and oxidation), surface complexation behavior and zero valent arsenic (i.e., As(0)) formation (Penke, 2016; Yan, 2012). The formation of $\operatorname{As}(0)$ onto adsorbent is useful in the prevention of post adsorption leaching effect of adsorbed arsenic back to the open environment. In this study we analyzed copper-based ternary metal oxides for arsenic mitigation by $\operatorname{As}(0)$ formation.

\section{EXPERIMENTAL}

$\mathrm{CuCl}_{2} \cdot 2 \mathrm{H}_{2} \mathrm{O}$ (Loba Chemie, India), $\mathrm{Al}\left(\mathrm{NO}_{3}\right)_{3} \cdot 9 \mathrm{H}_{2} \mathrm{O}$ (Merck, India), $\mathrm{Fe}\left(\mathrm{NO}_{3}\right)_{3} \cdot 9 \mathrm{H}_{2} \mathrm{O}$ and Liq. Ammonia (A.R. grade, Qualigens Chemicals, India) of A.R grade were used for synthesizing aluminum substituted copper ferrite as per the reported procedure. In preliminary qualitative studies, $100 \mathrm{~mL}$ aliquots of arsenic solutions $\left(57.6 \mu \mathrm{g} \mathrm{L}^{-1}\right.$ for As(III) and $24 \mu \mathrm{g} \mathrm{L}^{-1}$ for As(V)) were dispersed with $0.1 \mathrm{~g}$ of $\mathrm{Cu}-$ $\mathrm{Al}-\mathrm{Fe}$ adsorbent and agitated for $24 \mathrm{~h}$ using an orbital shaker at $\mathrm{pH}$ 7. The supernatant solutions were vacuum filtered using membrane filters. The separated adsorbent powders were dried and further preceded for IR, Raman and XPS studies. For XPS analysis of aliquot systems, filtered adsorption isotherms aliquots $\left(C_{\mathrm{i}} \sim 100 \mathrm{mg} \mathrm{L}^{-1}\right)$ were evaporated under natural conditions at R.T in open atmosphere and scratched samples were proceeded for characterization. The supernatant aqueous solutions were advanced to ICP-MS based quantitative analysis. In quantitative analysis adsorption isotherm $(24 \mathrm{~h})$, absorption kinetics $(6 \mathrm{~h})$ and $\mathrm{pH}$ variation studies were performed. In all adsorption systems $\mathrm{pH}$ adjustment was done using standard $\mathrm{HCl}(1 \mathrm{M})$ and $\mathrm{NaOH}(1 \mathrm{M})$ solution.

\section{RESULTS AND DISCUSSION}

\subsection{FESEM and vibrational spectroscopy results}

After the arsenic adsorption agglomeration, and flocculation behavior was observed in adsorbent powders. This agglomeration and flocculation behavior which may be due to the formation of different immobilized arsenic species (As-O-M kind). This kind of studies were earlier reported for various metal-based (e.g., $\mathrm{Fe}$, and $\mathrm{Al}$ ) adsorbent systems. The weight percentage (i.e., EDS spectra) of arsenic onto these adsorbents is observed around 0.9 and $0.4 \mathrm{wt} . \%$ for $\mathrm{As}(\mathrm{III})$ and $\mathrm{As}(\mathrm{V})$ systems (Fig. 1). Vibrational spectra at $\mathrm{pH} 7$ systems were observed with signals around 796, and $834 \mathrm{~cm}^{-1}$ for arsenic ( $\mathrm{As}(\mathrm{III})$, and $\left.\mathrm{As}(\mathrm{V})\right)$ adsorbed systems (Fig. 1). These vibrational spectra signals observed in the $800-850 \mathrm{~cm}^{-1}$ band inform the formation of various arsenic surface complex structures (e.g., As-O, As- $\mathrm{OH}$ ) of $v$ and $v_{\text {as }}$ kind. 